\title{
PI3K $\gamma$ activity in leukocytes promotes adipose tissue inflammation and early-onset insulin resistance during obesity
}

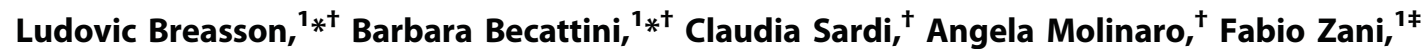 \\ Romina Marone, ${ }^{2}$ Fabrizio Botindari, ${ }^{2}$ Mélanie Bousquenaud, ${ }^{1}$ Curzio Ruegg, ${ }^{1}$ \\ Matthias P. Wymann, ${ }^{2 \S}$ Giovanni Solinas $^{1+\S}$
}

\begin{abstract}
The phosphoinositide 3-kinase $\gamma$ (PI3K $\gamma$ ) plays a major role in leukocyte recruitment during acute inflammation and has been proposed to inhibit classical macrophage activation by driving immunosuppressive gene expression. $\mathrm{PI} 3 \mathrm{~K} \gamma$ plays an important role in diet-induced obesity and insulin resistance. In seeking to determine the underlying molecular mechanisms, we showed that PI3K $\gamma$ action in high-fat diet-induced inflammation and insulin resistance depended largely on its role in the control of adiposity, which was due to PI3K $\gamma$ activity in a nonhematopoietic cell type. However, PI3K $\gamma$ activity in leukocytes was required for efficient neutrophil recruitment to adipose tissue. Neutrophil recruitment was correlated with proinflammatory gene expression in macrophages in adipose tissue, which triggered insulin resistance early during the development of obesity. Our data challenge the concept that PI3K $\gamma$ is a general suppressor of classical macrophage activation and indicate that PI3K $\gamma$ controls macrophage gene expression by non-cell-autonomous mechanisms, the outcome of which is context-dependent.
\end{abstract}

\section{INTRODUCTION}

Obesity is a major metabolic derangement that affects millions of people and is a causal factor for several debilitating diseases including type 2 diabetes, cardiovascular diseases, and several types of cancer. Although the mechanisms linking obesity to its associated diseases are still largely unresolved, saturation of adipocyte lipid storage capacity, ectopic lipid deposition, and metabolic inflammation is a concomitant event and hallmark of obesity-associated diseases (1-4). Furthermore, increasing evidence indicates that obesity causes alterations of gut microbiota leading to a low-grade metabolic endotoxemia, which may further promote obesity-associated inflammation through Toll-like receptor 4 signaling $(5,6)$. Thus, signal transducers operating at the interface between innate immunity and metabolic homeostasis may play a pivotal role in promoting obesity-associated diseases. The phosphoinositide 3-kinase $\gamma(\mathrm{PI} 3 \mathrm{~K} \gamma)$ is a potent signal transducer, which is activated by several signals implicated in innate immunity, including chemokines and bacterial lipopolysaccharides (LPS) (7-11). PI3K $\gamma$ has been reported to be a key inhibitor of classical activation of macrophages and a promoter of immunosuppressive gene expression in these cells that enable cancer cells to evade the immune system (12-15). PI3K $\gamma$ is also activated by adrenergic signaling $(16,17)$, which plays a potent role in several metabolic processes including lipolysis and adaptive thermogenesis. Studies from our laboratory and from our colleagues indicate that PI $3 \mathrm{~K} \gamma$ plays a central role in the progression of diet-induced obesity, metabolic inflammation, and insulin resistance $(18,19)$. Furthermore, pharmacological inhibition of $\mathrm{PI} 3 \mathrm{~K} \gamma$ is a promising strategy for the treatment of obesity-related diseases $(20,21)$. Two distinct mechanisms

\footnotetext{
${ }^{1}$ Department of Medicine/Physiology, University of Fribourg, 1700 Fribourg, Switzerland. ${ }^{2}$ Cancer and Immunobiology Laboratory, Department of Biomedicine, University of Basel, 4058 Basel, Switzerland.

*These authors contributed equally to this work.

tPresent address: Wallenberg Laboratory, Department of Molecular and Clinical Medicine, University of Gothenburg, 41345 Gothenburg, Sweden.

¥Present address: Cancer Research UK Beatson Institute, Switchback Road, Glasgow G61 1BD, UK.

§Corresponding author. Email: giovanni.solinas@wlab.gu.se (G.S.); matthias.wymann@ unibas.ch (M.P.W.)
}

have been put forward to explain the action of PI3K $\gamma$ in diet-induced obesity and insulin resistance. One mechanism proposes that PI3K $\gamma$ in myeloid cells promotes obesity-driven metabolic inflammation, leading to insulin resistance and altered hepatic expression of genes involved in lipid handling and metabolism, thereby promoting fatty liver (19). The second mechanism emphasizes the role of PI3K $\gamma$ as an inhibitor of hormone-sensitive lipase (HSL) activation and of adaptive thermogenesis (18). According to the latter model, PI3K $\gamma$ activity within a nonhematopoietic cell type promotes excessive adiposity and, consequently, steatosis, metabolic inflammation, and insulin resistance (18). However, current evidence does not establish a cause-and-effect relationship between the involvement of PI3K $\gamma$ in adiposity and metabolic inflammation. Hence, the mechanism of action of PI3K $\gamma$ in dietinduced obesity and insulin resistance is still largely unresolved. Here, we investigated the key elements of the two mechanisms described above in mice with systemic ablation of PI3K $\gamma$ in models of dietary and genetic obesity, in mice with tissue-specific inactivation of PI3K $\gamma$, and in cultured myeloid cells lacking PI3K $\gamma$. Our results clarify the role of PI3K $\gamma$ in diet-induced inflammation and insulin resistance and challenge the concept that PI3K $\gamma$ is a general inhibitor of classical macrophage activation.

\section{RESULTS}

Systemic PI3K $\gamma$ ablation protects mice from obesity, inflammation, and insulin resistance caused by high-fat diet feeding

To establish the hierarchical importance of the two models proposed for $\mathrm{PI} 3 \mathrm{~K} \gamma$ action in obesity and insulin resistance $(18,19)$, it was necessary to recapitulate the essential elements of these models in the same cohort of mice. Thus, we first investigated these elements in mice with systemic ablation of PI3K $\gamma\left(P I 3 \mathrm{K \gamma}^{-1-}\right)$ and diet-induced obesity. Compared to control mice, $\mathrm{PI} 3 \mathrm{~K}^{-1-}$ mice were protected from diet-induced obesity (fig. S1A), insulin resistance (fig. S1, B and C), and hepatic steatosis (fig. S1D). In parallel, hepatic expression of genes implicated in lipid handling and metabolism was reduced (fig. S1E). Phosphorylation of 
HSL at the protein kinase A (PKA) sites $\operatorname{Ser}^{563}$ and $\operatorname{Ser}^{660}$, but not at the AMP-activated protein kinase (AMPK) site $\mathrm{Ser}^{565}$, was increased in adipose tissue from $\mathrm{PI} 3 \mathrm{~K}^{-1-}$ mice (fig. S1, F and G), indicating increased PKAdriven lipolysis in these mice. Furthermore, $P I 3 \mathrm{K \gamma}^{-1-}$ mice were protected from metabolic inflammation, as showed by decreased expression of inflammatory markers in liver (fig. S2A) and reduced macrophage accumulation in white adipose tissue (fig. S2, B and C). In addition, the adipose tissue of $P I 3 \mathrm{~K}^{-1-}$ mice showed reduced expression of markers for classical M1 macrophage activation and increased expression of the gene encoding matrix metalloproteinase 9 (MMP-9), a tissue remodeling protein and a marker for alternative M2 macrophage activation (fig. S2D) $(22,23)$.

\section{Systemic PI3K $\gamma$ ablation partially protects $o b / o b$ mice from inflammation and insulin resistance but not obesity}

$\mathrm{PI} 3 \mathrm{~K} \gamma$ ablation in the $o b / o b$ background protects from insulin resistance and metabolic inflammation independently from differences in adiposity (19). To test whether PI3K $\gamma$ action in obesity depends on its role on the promotion of adiposity, we generated mice lacking $\mathrm{PI} 3 \mathrm{~K} \gamma$ in the $o b / o b$ background $\left(o b / o b-P I 3 K \gamma^{-/-}\right)$. At 9 and 16 weeks of age, ob/ob-PI3K $\gamma^{-1-}$ mice had similar body weights as $o b / o b$ controls and a marginal but significant reduction in body lipids (Fig. 1, A and B). The loss of protection from diet-induced obesity correlated with the loss of HSL activation in this model (Fig. 1, C and D).

- Consistent with these findings, adipocyte size distribution was similar between $o b / o b$ and $o b / o b-P I 3 K \gamma^{-1-}$ mice (Fig. 1E). Between 8 and 9 weeks of age, $o b / o b-P I 3 K \gamma^{-1-}$ mice showed improved glucose and insulin tolerance (Fig. 1, F and G). However, this improvement was smaller than that observed in the diet-induced obesity model (fig. S1, B and C) and was largely transient, because by the age of 15 to 16 weeks, insulin and glucose tolerance were similar in $o b / o b$ and $o b / o b-P I 3 K^{-/-}$mice (Fig. 1, H and I). Analysis of the area under the curve of the glucose and insulin tolerance tests also confirmed that loss of PI3K $\gamma$ in $o b / o b$ mice led to a partial and transient protection from insulin resistance (Fig. 1J). Liver steatosis, hepatic proinflammatory gene expression profile, and expression of genes implicated in lipid handling and metabolism were similar in livers from $o b / o b-P I 3 K^{-1-}$ and control $o b / o b$ mice at different time points (fig. S3, A to F). Macrophage recruitment to crown-like structures and expression of macrophage markers were similar in adipose tissue from $o b / o b-P I 3 K^{-l-}$ mice and that from control ob/ob mice (Fig. 2, A to E). However, we observed that loss of PI3K $\gamma$ shifted gene expression of macrophages in adipose tissue from markers of $\mathrm{M} 1$ polarization to markers of M2 activation (Fig. 2, F and G). At the age of 9 weeks, ob/ob$P I 3 \mathrm{Kr}^{-1-}$ mice showed reduced adipose tissue expression of some M1 markers (TNF $\alpha, M I P-1 \alpha$, and RANTES) and increased expression of the M2 marker MMP-9 compared to controls (Fig. 2F). Moreover, in the adipose tissue from 16-week-old $o b / o b-P I 3 K^{-/-}$mice, the expression of all the measured M1 markers was similar to controls, but that of M2 markers (Arg-1, MRC-1, MRC-2, and MMP-9) was increased in adipose

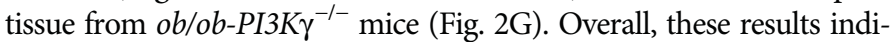
cate that loss of PI3K $\gamma$ in the ob/ob model did not significantly affect the development of adiposity, fatty liver, hepatic inflammation, and, in contrast to a previous report (19), the accumulation of adipose tissue macrophages. However, PI $3 \mathrm{~K} \gamma$ ablation in $o b / o b$ mice led to a partial and transient improvement of insulin sensitivity, which correlated with an adipose tissue gene expression signature indicating a partial M1 to M2 polarization of adipose tissue macrophages.
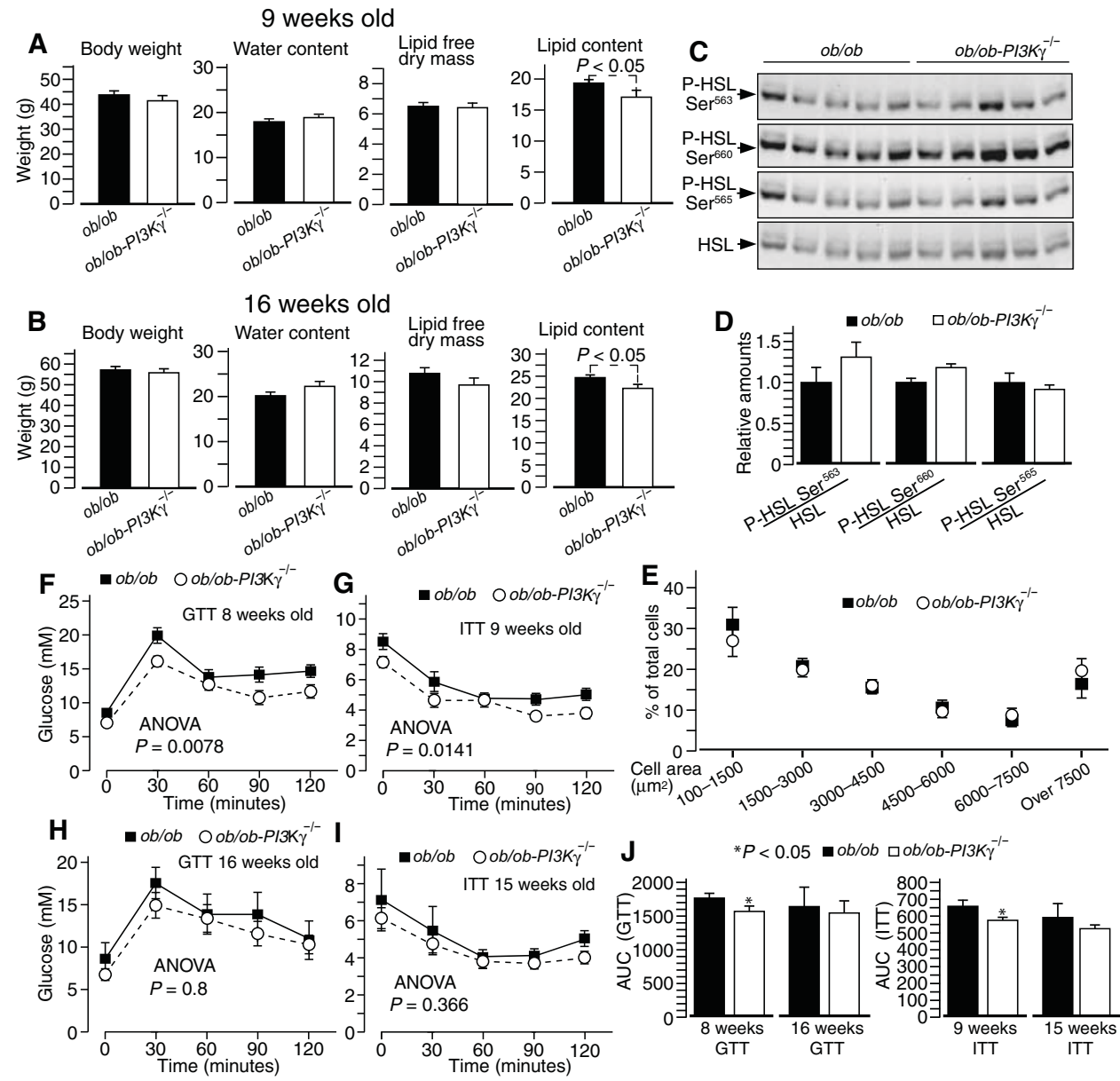

Fig. 1. $\mathrm{PI} 3 \mathrm{~K} \gamma$ ablation in $o b / o b$ mice leads to a partial and largely transient protection from insulin resistance independently from adiposity. (A) Body weight and body composition of 9-week-old ob/ob and ob/ob-PI3K $\gamma^{-1-}$ mice

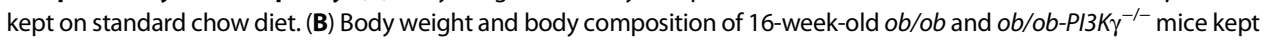
on standard chow diet. (C) HSL phosphorylation at PKA sites ( $\mathrm{Ser}^{563}$ and $\mathrm{Ser}^{660}$ ) and AMPK site (Ser ${ }^{565}$ ) in epididymal adipose tissue from 16-week-old $\mathrm{ob} / \mathrm{ob}$ and $\mathrm{ob} / \mathrm{ob}-\mathrm{PI}_{3} \mathrm{Kr}^{-/-}$mice. (D) Quantification of HSL phosphorylation data from the immunoblots in (C). (E) Adipocyte size distribution of 16-week-old ob/ob and ob/ob-PI3K $\gamma^{-1-}$ mice in (D). (F) Glucose

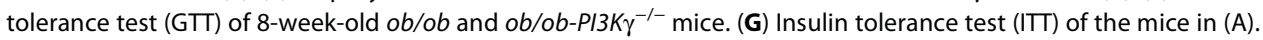
(H) Glucose tolerance test of the mice described in (B). (I) Insulin tolerance test of 15 -week-old $o b / o b$ and $o b / o b-P / 3 K^{-1-}$ mice. (J) Area under the curve (AUC) of the glucose and insulin tolerance tests. Data are means, SEs are indicated, and $P$ values are calculated by Wilcoxon-Mann-Whitney test and two-way analysis of variance (ANOVA) for glucose tolerance test and insulin tolerance test curves. (A and $\mathrm{B}$ ) $n=7$ to 9 mice per genotype; ( $\mathrm{C}$ to $\mathrm{E}$ ) $n=5$ mice per genotype; ( $\mathrm{F}$ to J) $n=9$ to 10 mice per genotype. 

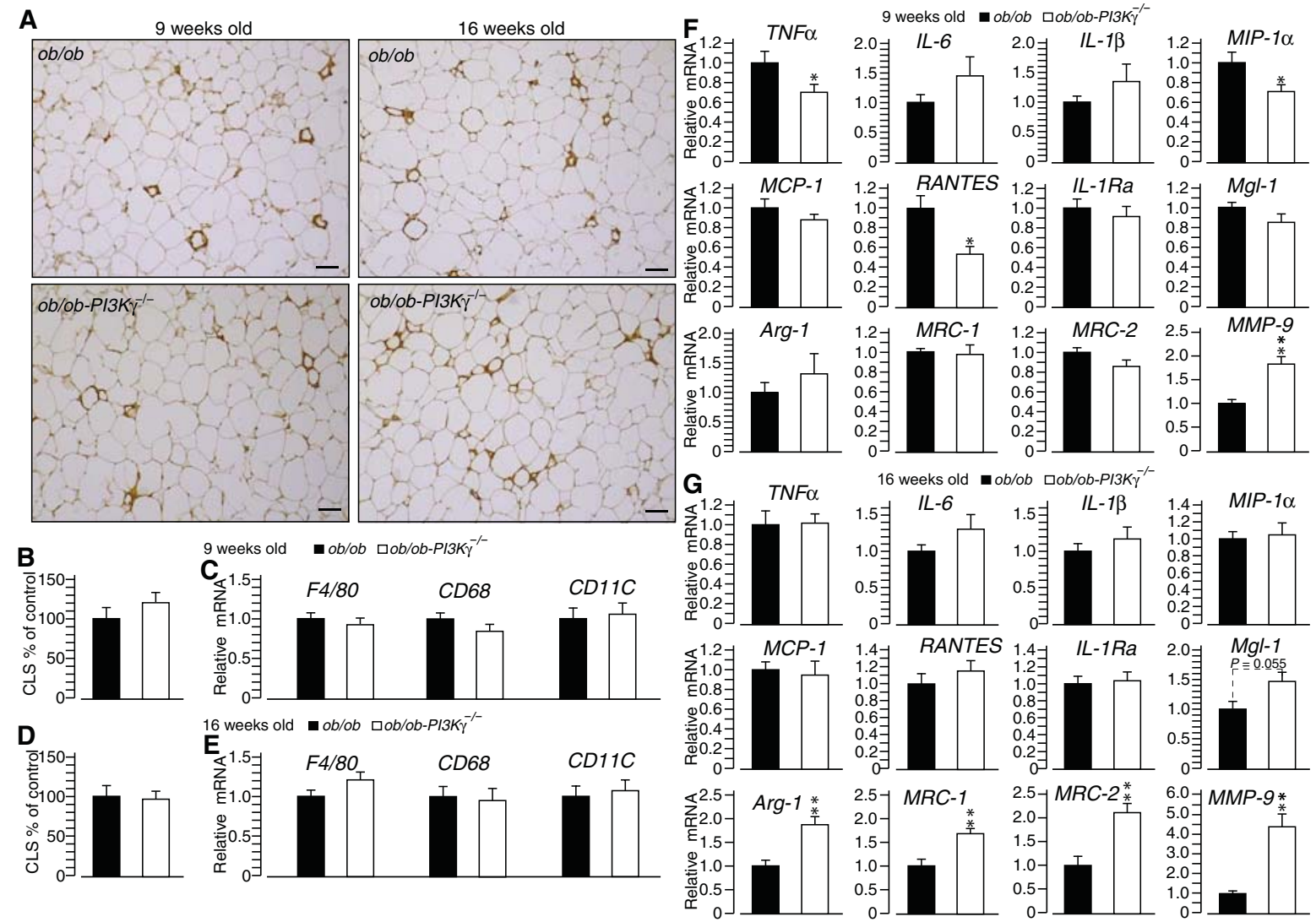

Fig. 2. PI3K $\gamma$ ablation in ob/ob mice drives an M2-biased gene expression signature in adipose tissue. (A) Mac-2 staining of epididymal adipose tissue sections from 9-and 16-week-old $o b / o b$ and $o b / o b-P I 3 K_{\gamma}{ }^{-1-}$ mice. Scale bars, $100 \mu \mathrm{m}$. (B) Quantification of the number of crown-like structures (CLS) in adipose tissue of 9-week-old $o b / o b$ and $o b / o b-$ $P I 3 \mathrm{K \gamma}^{-1-}$ mice in (A). (C) Expression of macrophage markers in adipose tissue from 9-week-old ob/ob and ob/ob-PI3K $\gamma^{-1-}$ mice. (D) Quantification of the number of crown-like

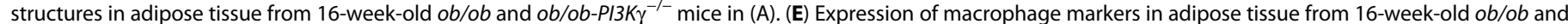
$o b / o b-P I 3 K^{-1-}$ mice. (F) Expression of markers for M1- and M2-activated macrophages in adipose tissues of 9-week-old ob/ob and ob/ob-PI3K ${ }^{-1-}$ mice. (G) Expression of markers for M1- and M2-activated macrophages in the adipose tissue of 16-week-old ob/ob and ob/ob-PI3K $\gamma^{-1-}$ mice. Data are means, SEs are indicated, and $P$ values are calculated by Wilcoxon-Mann-Whitney test. $n=5$ mice per group for (A) (16 weeks old) and (D); $n=8$ to 13 mice per group for all other data.

Targeting PI3K $\gamma$ in lysozyme M-expressing myeloid cells alters the gene expression profile of obese adipose tissue To investigate the role of $\mathrm{PI} 3 \mathrm{~K} \gamma$ activity in adipose tissue macrophages during obesity, we generated conditional knockout $(\mathrm{KO})$ mice lacking $\mathrm{PI} 3 \mathrm{~K} \gamma$ in lysozyme M-expressing myeloid cells $\left(P I 3 K \gamma^{L y s M}\right)$ by CreLoxP recombination. More specifically, mice with the exons 3 and 4 of Pi3k flanked by LoxP sites (PI3K $\gamma^{F / F}$; fig. S4, A and B) were crossed with mice expressing the cre recombinase under the control of the lysozyme-M promoter, which is expected to drive a selective cre recombination in most myeloid cells. Immunoblot analysis showed that PI3K $\gamma$ protein abundance was reduced by about $80 \%$ in bone marrow-derived macrophages (BMDMs) and by about $50 \%$ in total adipose tissue and adipose tissue stromal vascular fraction of $P I 3 K \gamma^{L y s M}$ mice compared to $P I 3 K \gamma^{F / F}$ control mice (fig. S5, A to C). These data indicated that the efficiency of Pi3k deletion in adipose tissue myeloid cells of $P I 3 K \gamma^{L y s M}$ mice was partial. We observed a marginal nonsignificant tendency for improved insulin tolerance for 12-week-old $P I 3 K \gamma^{L y s M}$ mice (fig. S6B). However, $P I 3 K \gamma^{L y s M}$ and littermate $P I 3 K \gamma^{F / F}$ mice showed similar body weights, insulin sensitivity, and liver histology (fig. S6, A and $\mathrm{C}$ to $\mathrm{H}$ ). Hepatic expression of lipid-handling genes and phosphorylation of HSL at the PKA sites in adipose tissue were also similar between $P I 3 K \gamma^{F / F}$ and $P I 3 K \gamma^{L y s M}$ mice (fig. S6, I to K). Hepatic expression of M1 and M2 markers was also similar between genotypes, although we observed increased expression of MIP-1 $\alpha$ (an M1 cytokine) and of MRC-2 (an M2 marker) in the livers of $P I 3 K \gamma^{L y s M}$ mice (fig. S7A). The number of crown-like structures and the mRNA abundance of the macrophage marker F4/80 in adipose tissue were also similar between genotypes (fig. S7, B to D). However, we observed that the expression of CD68 and $C D 11 C$ (two markers for adipose tissue macrophages), $I L-1 R a$ and MIP-1 $\alpha$ (two markers of M1 activation), and Arg-1, MRC-1, and $M M P-9$ (three markers of M2 activation) was increased in adipose tissues from $P I 3 K \gamma^{L y s M}$ mice. Overall, these results indicate that during obesity, $\mathrm{PI} 3 \mathrm{~K} \gamma$ activity in lysozyme $\mathrm{M}$-expressing myeloid cells is dispensable for macrophage accumulation in adipose tissue but is required for the efficient polarization of adipose tissue macrophage toward the M1 phenotype.

\section{PI3K $\gamma$ activity within the hematopoietic-endothelial compartment promotes insulin resistance and M1 gene expression in adipose tissue during obesity}

Because Pi3k $\gamma$ was partially deleted in adipose tissue myeloid cells from $P I 3 K \gamma^{L y s M}$ mice (fig. S5A), and because nonmyeloid leukocytes are implicated in promoting classical M1 activation of adipose tissue macrophages in obesity (24-26), we generated mice with conditional ablation of PI3K $\gamma$ in hematopoietic and endothelial cells $\left(P I 3 K \gamma^{H E}\right) . P I 3 K \gamma^{F / F}$ 
mice were crossed with mice expressing the Cre recombinase under the control of the Tek (Tie-2) promoter, which drives specific LoxP recombination in endothelial cells and in hematopoietic progenitor cells during embryogenesis, and thus in the whole hematopoietic system (27). $P I 3 K \gamma^{H E}$ male mice did not show substantial recombination in brain and liver, and we observed about $30 \%$ of recombination in skeletal muscle, which can at least in part be explained by recombination in endothelial and hematopoietic cells (fig. S8A). We observed about $50 \%$ of genetic recombination in white adipose tissue, more than $80 \%$ of recombination in adipose tissue stromal-vascular fraction, and essentially a complete recombination in BMDMs, bone marrow, and spleen (fig. S8A). Immunoblot analysis revealed that PI3K $\gamma$ was ablated in BMDMs, reduced by more than $80 \%$ in whole white adipose tissue, and completely ablated in the adipose tissue stromal-vascular fraction (fig. S8, B and C). Compared to $P I 3 K \gamma^{F / F}$ mice on a high-fat diet, $P I 3 K \gamma^{H E}$ mice on the same diet had similar body weights but showed improved insulin tolerance and glucose tolerance at the age of 12 to 13 weeks (Fig. 3, A to E). However, this improved insulin sensitivity was largely transient, because by 21 to 22 weeks of age, $P I 3 K \gamma^{H E}$ mice showed only a small improvement in insulin tolerance and similar glucose tolerance as PI3K $\gamma^{F / F}$ control mice (Fig. 3, F to J). Steatosis, expression of genes implicated in lipid handling, HSL phosphorylation, and adipocyte size distribution were also similar between genotypes (Fig. 3, K to M, and fig. S9, B and C). We conclude that PI3K $\gamma$ activity in the hematopoietic-endothelial compartments contributes to the development of insulin resistance but not to steatosis and adiposity.

Hepatic inflammatory gene expression was similar between $P I 3 K \gamma^{H E}$ and $P I 3 K \gamma^{F / F}$ mice (fig. S9A). The number of crownlike structures in adipose tissue and the expression of macrophage markers were also similar between genotypes (Fig. 4, A to E). However, at the age of 12 weeks, $P I 3 K \gamma^{H E}$ mice showed reduced adipose tissue expression of the gene encoding the M1 cytokine tumor necrosis factor- $\alpha$ (TNF $\alpha)$ and increased expression of arginase (Fig. $4 \mathrm{~F})$. Furthermore, at the age of 23 weeks, the expression of several genes encoding M2 markers (Arg-1, MRC-1, MRC-2, and $M M P-9)$ was significantly increased in white adipose tissue from $P I 3 K \gamma^{H E}$ mice compared to that from $P I 3 K \gamma^{F / F}$ mice (Fig. 4G). Thus, PI3K $\gamma$ activity in hematopoietic and endothelial cells is dispensable for hepatic inflammation and adipose tissue macrophage recruitment but promotes an M1 gene expression profile in adipose tissue during obesity.

PI3K $\gamma$ in macrophages is required for AKT phosphorylation induced in response to $M 1$ and $M 2$ activating signals but plays a minor role in macrophage polarization

To investigate the cell-autonomous role of $\mathrm{PI} 3 \mathrm{~K} \gamma$ in macrophage activation, we analyzed AKT phosphorylation in BMDMs from $\mathrm{PI} 3 \mathrm{~K}^{-1-}$ mice and from wild-type (WT) control mice that were exposed to various stimuli. Palmitate (PA) treatment did not induce AKT phosphorylation above basal amounts in BMDMs, which were similar between

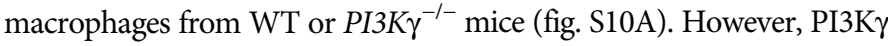
activity in BMDMs was required for efficient AKT phosphorylation not only in response to LPS and IFN $\gamma$ (interferon- $\gamma$ ), two potent activators of the M1 phenotype, but also in response to IL-4 (interleukin-4) and IL-13, two potent activators of the M2 phenotype (Fig. 5, A and B). Next, quantitative polymerase chain reaction (qPCR) analysis of markers of classical M1 activation and alternative M2 activation was performed on BMDMs from WT and $\mathrm{PI} 3 \mathrm{K \gamma}^{-1-}$ mice that were incubated with an M1 differentiation medium (LPS + IFN $\gamma$ ) or an M2 differentiation medium (IL-4 + IL-13). PI3K $\gamma$ activity in cultured BMDMs was not required for M1 activation in response to LPS and IFN $\gamma$, or for M2 activation in response to IL-4 and IL-13, because $P I 3 \mathrm{~K}^{-/-}$BMDMs showed M1 or M2 gene expression signatures under these experimental conditions (Fig. 5, C and D). However, we observed several small but significant differences in gene expression that, with the exception of $M C P-1$ in macrophages exposed to the M1 activation medium for 4 hours, or MGL-1 at 24 hours of M1 activation, are consistent with a role for $\mathrm{PI} 3 \mathrm{~K} \gamma$ in promoting macrophage polarization toward classical $\mathrm{M} 1$ activation (Fig. 5, C and D). Overall, our data indicate that PI3K $\gamma$
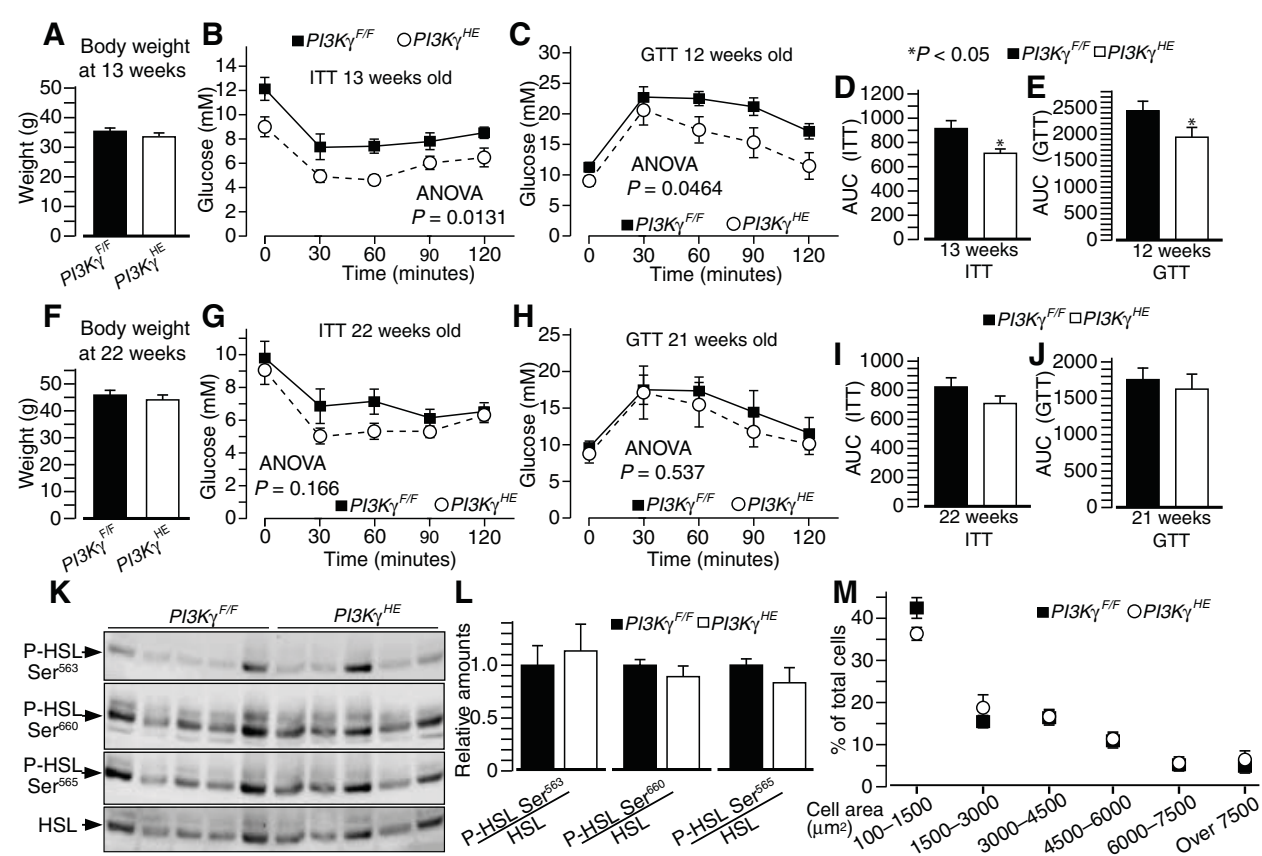

Fig. 3. PI3K $\gamma$ ablation in hematopoietic and endothelial cells partially protects from insulin resistance independently from differences in adiposity. (A) Body weight of high-fat diet-fed mice lacking Pi3k in hematopoietic and endothelial cells $\left(P I 3 K \gamma^{H E}\right)$ and $P I 3 K \gamma^{F / F}$ mice at the age of 13 weeks. (B) Insulin tolerance test of the mice in (A). (C) Glucose tolerance test of $P I 3 K \gamma^{F / F}$ and $P I 3 K \gamma^{H E}$ mice at the age of 12 weeks. (D) Area under the curve of the insulin tolerance test in (B). (E) Area under the curve of the glucose tolerance test in (C). (F) Body weight of 22-week-old $P I 3 K \gamma^{H E}$ and $P I 3 K \gamma^{F / F}$ mice on a high-fat diet. (G) Insulin tolerance test of the mice in (F). (H) Glucose tolerance test of 21-week-old $P I 3 K \gamma^{H E}$ and $P I 3 K \gamma^{F / F}$ mice on a high-fat diet. (I) Area under the curve of the insulin tolerance test in (G). (J) Area under the curve of the glucose tolerance test in (H). (K) HSL phosphorylation in epididymal adipose tissue from 23-week-old $P I 3 K \gamma^{H E}$ and $P I 3 K \gamma^{F / F}$ control mice on a high-fat diet. (L) Quantification of HSL phosphorylation data from the immunoblots in (K). (M) Adipocyte size distribution of 23-week-old PI3K $\gamma^{H E}$ and $P I 3 K \gamma^{F / F}$ mice on a high-fat diet. Data are means, SEs are indicated, and $P$ values are calculated by WilcoxonMann-Whitney test and two-way ANOVA for glucose tolerance test and insulin tolerance test curves. $n=8$ mice per group for $(A)$ to $(J)$, and $n=5$ to 6 mice per group for $(K)$ to $(M)$. 


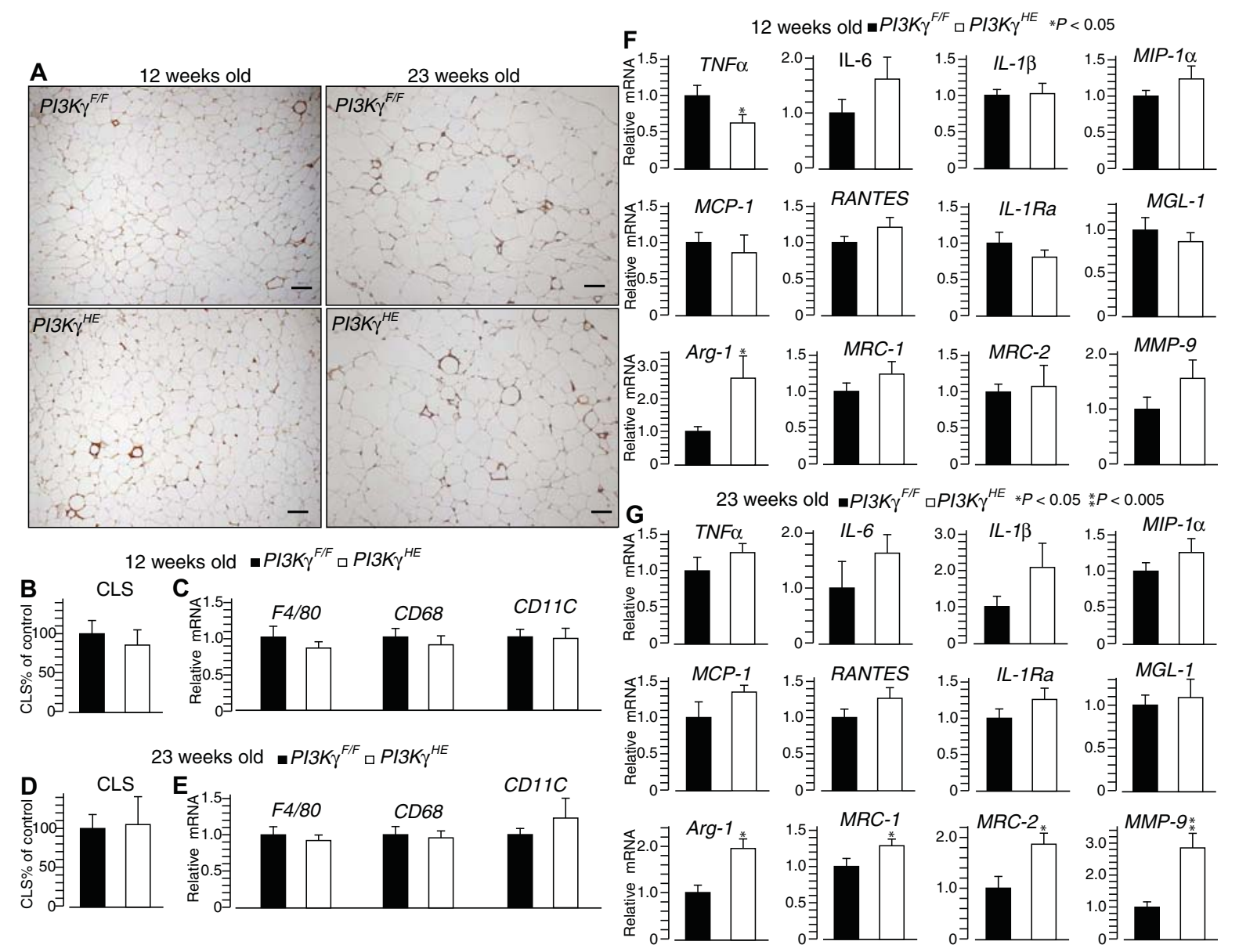

Fig. 4. PI3K $\gamma$ ablation in the hematopoietic-endothelial compartment drives an M2-biased gene expression signature in adipose tissue. (A) Mac-2 staining of epididymal adipose tissue sections from 12- and 23 -week-old $P I 3 K \gamma^{H E}$ and $P I 3 K \gamma^{F / F}$ control mice on a high-fat diet. Scale bars, $100 \mu \mathrm{m}$. (B) Quantification of the number of crown-like structures in adipose tissue in (A). (C) Expression of macrophage markers in adipose tissue from 12-week-old $P I 3 K^{H E}$ and $P I 3 K \gamma^{F / F}$ mice on a high-fat diet. (D) Quantification of the number of crown-like structures in adipose tissue from 23-week-old $P I 3 K \gamma^{H E}$ and $P I 3 K \gamma^{F / F}$ mice on a high-fat diet. (E) Expression of macrophage markers in adipose tissue from 23-week-old $P I 3 K \gamma^{H E}$ and $P I 3 K \gamma^{F / F}$ mice on a high-fat diet. (F) Expression of markers for M1-and M2-activated macrophages in adipose tissue from 12 -week-old $P I 3 K \gamma^{H E}$ and $P I 3 K \gamma^{F / F}$ mice kept on a high-fat diet. (G) Expression of markers for M1- and M2-activated macrophages in adipose tissue from 23 -week-old $P I 3 K^{H E}$ and $P I 3 K \gamma^{F / F}$ mice on a high-fat diet. Data are means, SEs are indicated, and $P$ values are calculated by Wilcoxon-Mann-Whitney test. $n=5$ to 11 mice per group for (A) to (G).

activity in macrophages is required for AKT signaling in response to major M1 and M2 polarization signals and plays a modest action in promoting M1-polarized gene expression.

\section{Loss of PI3K $\gamma$ activity has a modest effect on signaling cascades driving $M 1$ and $M 2$ macrophage activation}

BMDMs from WT or $\mathrm{PI} 3 \mathrm{~K}^{-1-}$ mice were exposed to various macrophage-activating signals to evaluate the role of PI3K $\gamma$ activity in key signaling pathways driving classical or alternative macrophage activation. Loss of PI3K $\gamma$ did not affect LPS-mediated induction of the kinases JNK (c-Jun N-terminal kinase) and p38, although we observed a trend

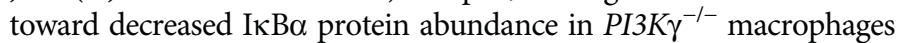
after LPS stimulation (Fig. 6A and fig. S10B). However, this trend did not reach statistical significance, and $\mathrm{I} \kappa \mathrm{B} \alpha$ protein abundance was similar between WT and $P I 3 \mathrm{K \gamma}^{-1-}$ macrophages costimulated with LPS and IFN $\gamma$ (Fig. 6B). Signal transducer and activators of transcription 1 (STAT1) phosphorylation in macrophages exposed to IFN $\gamma$, or LPS plus IFN $\gamma$, and STAT6 phosphorylation in macrophages treated with IL-4 were not affected by ablation of PI3K $\gamma$ (Fig. 6, A to C). However,
STAT6 phosphorylation after 2 hours of IL-13 stimulation was significantly increased in $\mathrm{PI} 3 \mathrm{~K}^{-1-}$ macrophages compared to control WT macrophages (Fig. 6, C and D). Together, these results challenge the previously proposed role for PI3K $\gamma$ in the control of I $\mathrm{B} \alpha$ degradation in macrophages (14) and indicate that PI3K $\gamma$ activity in these cells reduces STAT6 phosphorylation after prolonged exposure to IL-13.

\section{$\mathrm{PI} 3 \mathrm{~K} \gamma$ activity is required for efficient neutrophil recruitment to adipose tissue}

Our data from cultured BMDMs indicated that the M2-polarized gene expression in adipose tissue of mice lacking $\mathrm{PI} 3 \mathrm{~K} \gamma$ was most likely caused by non-cell-autonomous mechanisms. Because different types of leukocytes are implicated in adipose tissue macrophage polarization by controlling the local abundance of IFN $\gamma$, IL-4, and IL-13, we measured the concentration of these cytokines in the adipose tissue of mice lacking PI3K $\gamma$. Compared to their controls, ob/ob-PI3K $\gamma^{-/-}$and $P I 3 K \gamma^{H E}$ mice displayed similar IFN $\gamma$ concentration in adipose tissue, and IL-13 was slightly increased in adipose tissue from $\mathrm{ob} / \mathrm{ob}-\mathrm{PI} 3 \mathrm{~K} \gamma^{-1-}$ mice but not in adipose tissue from $P I 3 K \gamma^{H E}$ mice (fig. S11, A and B). 

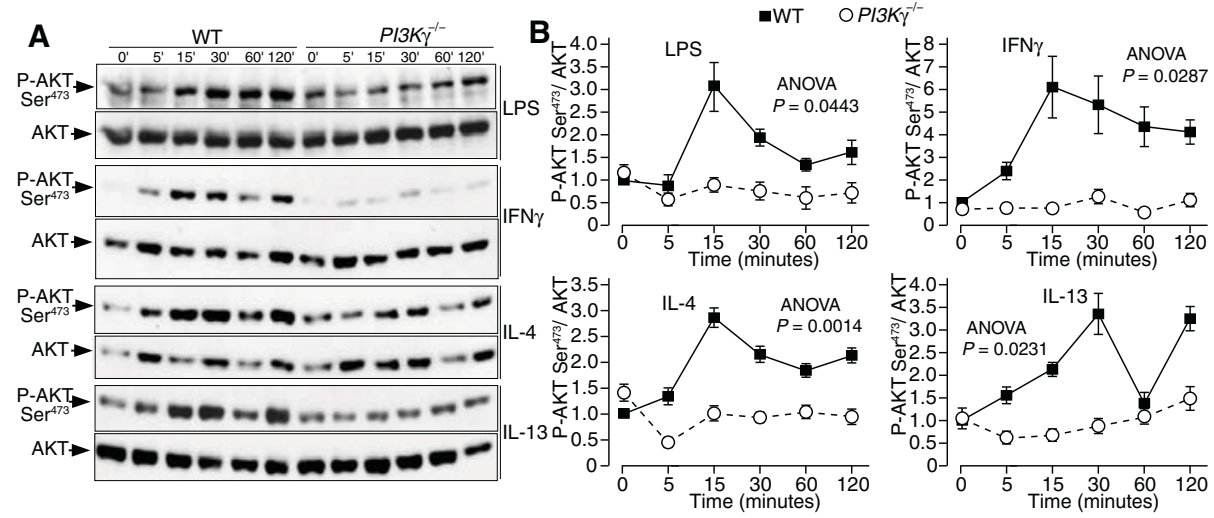

C
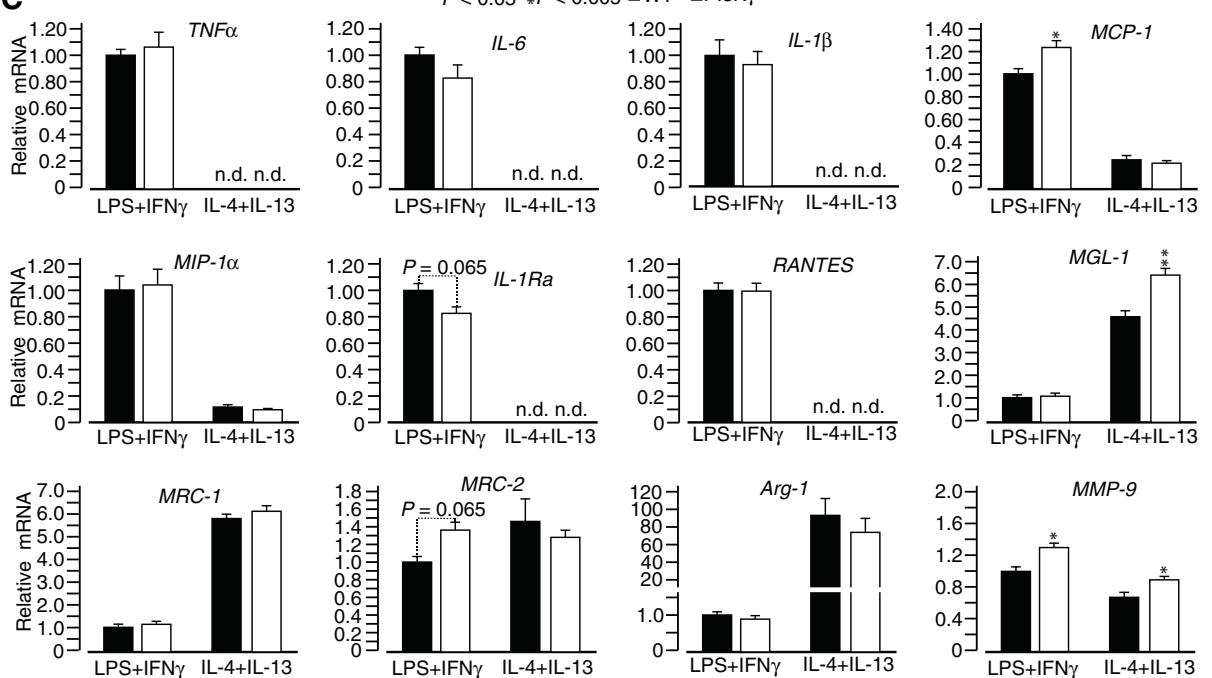

D
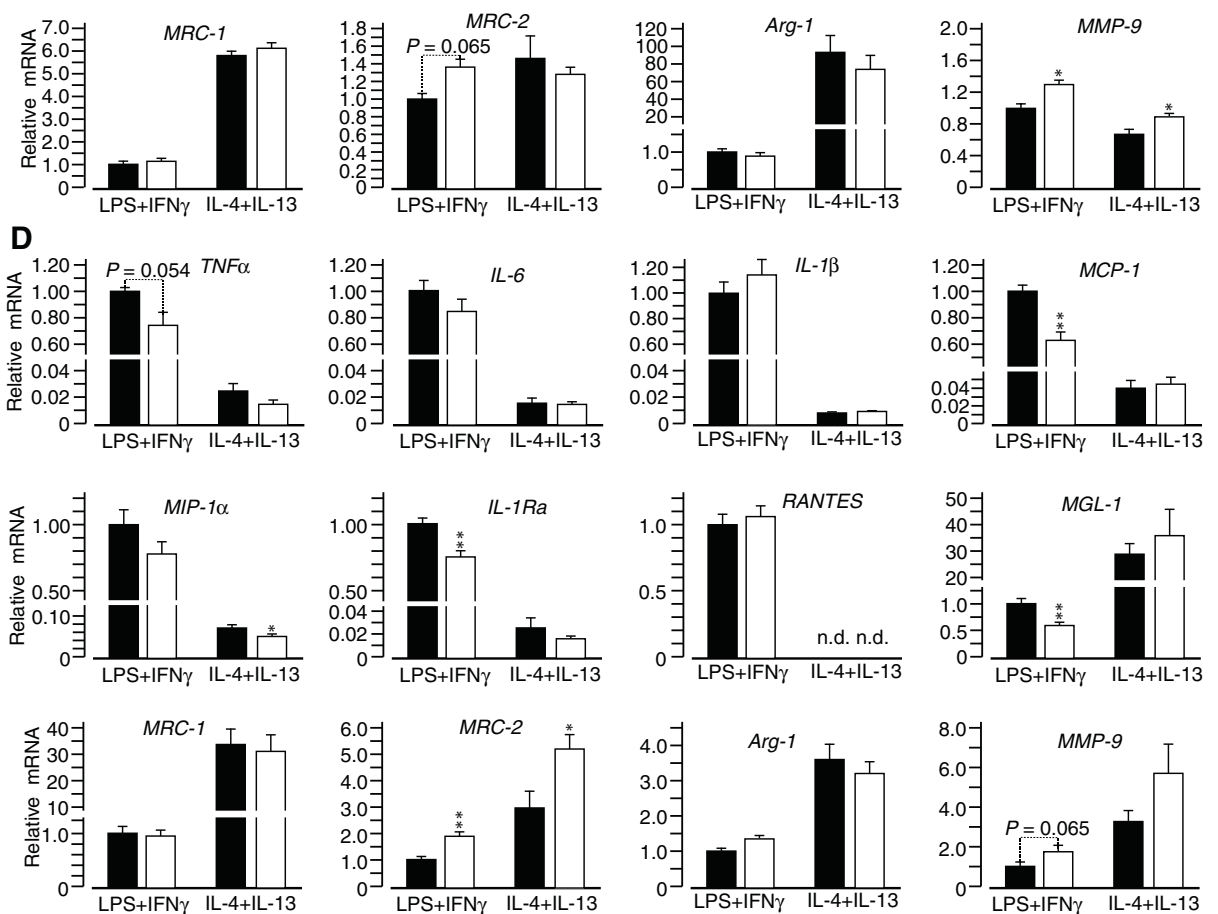

Fig. 5. PI3K $\gamma$ in macrophages is required for AKT activation in response to signals driving $M 1$ and $M 2$ activation but is only partially required for polarized gene expression. (A) Immunoblot analysis of AKT phosphorylation

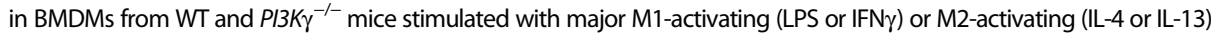
signals. (B) Quantification of relative AKT Ser ${ }^{473}$ phosphorylation from the immunoblots in (A). (C) Expression of $\mathrm{M} 1$ and M2 markers in BMDMs from WT and $\mathrm{Pl3K \gamma}^{-1-}$ mice exposed for 4 hours to an M1 differentiation medium (LPS + IFN $\gamma$ ) or to an M2 differentiation medium (IL-4 + IL-13). n.d., not detectable. (D) Expression of M1 and M2 markers in BMDMs from WT and PI3K $\gamma^{-1-}$ mice exposed for 24 hours to M1 or M2 differentiation medium. Data are means, SEs are indicated, and $P$ values are calculated by two-way ANOVA for (B) and Wilcoxon-Mann-Whitney test for (C) and (D). $n=3$ mice per group for (A) and (B), and $n=6$ to 8 mice per group for (C) and (D).
Furthermore, adipose tissue abundance of IL- 4 was unchanged in $o b / o b-P I 3 K^{-1-}$ mice and was significantly reduced in $P I 3 K \gamma^{H E}$ mice compared to controls (fig. S11, A and B). Together, these results indicate that PI $3 \mathrm{~K} \gamma$ activity in leukocytes does not generally alter adipose tissue abundance of IFN $\gamma$, IL-4, and IL-13. Gene expression analysis of endothelial cell activation also indicates that loss of PI3K $\gamma$ did not significantly affect activation of endothelial cells in the obese adipose tissue (fig. S11, C and D). Adipose tissue neutrophils have been implicated in obesity-driven M1 polarization of adipose tissue macrophages by an unknown mechanism that does not involve changes in the local concentrations of IFN $\gamma$, IL-4, and IL-13 (28). Because PI3K $\gamma$ plays a major role in neutrophil chemotaxis during acute inflammation (29), we evaluated the role of PI3K $\gamma$ in the recruitment of neutrophils to adipose tissue. Compared to controls,

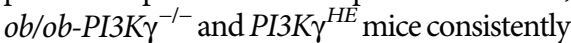
had fewer adipose tissue neutrophils (defined as $\mathrm{CD} 11 \mathrm{~b}^{+} \mathrm{Ly}_{6 \mathrm{G}}{ }^{+}$cells) at two different time points (Fig. 7, A to D). Together, our results indicate that PI3K $\gamma$ activity in the hematopoieticendothelial compartment does not affect adipose tissue concentrations of IFN $\gamma$, IL-4, and IL-13, or endothelial cell activation, but is required for efficient recruitment of neutrophils to adipose tissue.

\section{DISCUSSION}

Our results clarified the mechanism of action of PI3K $\gamma$ in obesity-driven inflammation and insulin resistance and challenged the current view on the role of PI3K $\gamma$ in the control of macrophage activation and gene expression $(12-14,30)$. Our data indicated that $\mathrm{PI} 3 \mathrm{~K} \gamma$ action in metabolic inflammation and insulin resistance is largely dependent on its role in the promotion of diet-induced adiposity, which was correlated with PKA-mediated phosphorylation of HSL in white adipose tissue. Nonetheless, our data on PI3K $\gamma$ ablation in $o b / o b$ mice and tissue-specific deletion of PI3K $\gamma$ in mice made obese by high-fat diet feeding indicated that $\mathrm{PI} 3 \mathrm{~K} \gamma$ activity in leukocytes contributes to obesity-driven insulin resistance. The progression of obesity is characterized by polarization of adipose tissue macrophages from an "M2" tissue remodeling phenotype (typical of lean mice) toward an inflammatory "M1" activation status, characterized by a switch of the gene expression signature in the whole adipose tissue $(23,31-34)$. Here, we showed that PI3K $\gamma$ activity in leukocytes was required for efficient M1-polarized gene 


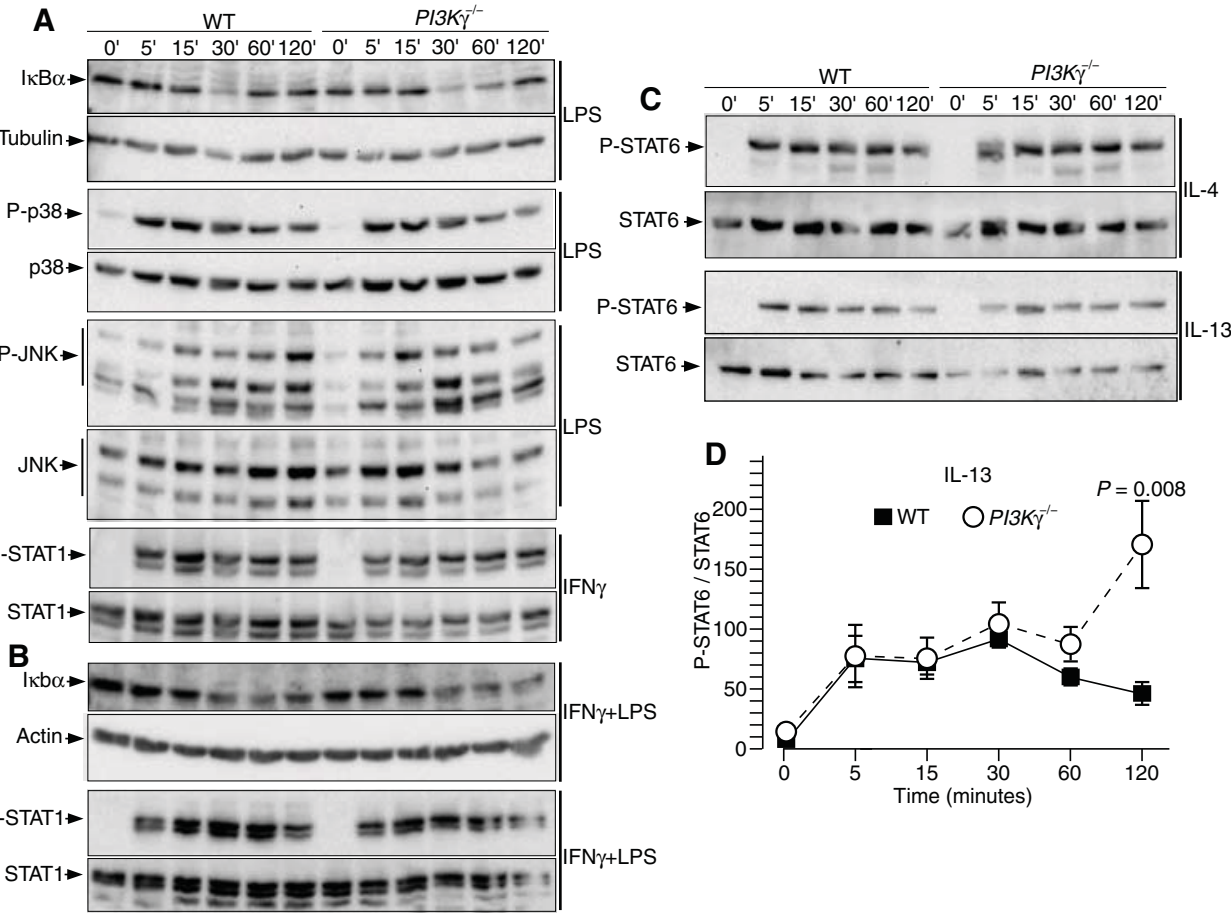

Fig. 6. M1- and M2-polarizing signaling in macrophages lacking PI3K $\gamma$. (A) Immunoblot analyses of $\mid \kappa B \alpha$ degradation and p38 and JNK phosphorylation induced in BMDMs exposed to LPS for the indicated times and STAT1 phosphorylation in BMDMs treated with IFN $\gamma$ for the indicated times. (B) Immunoblot analyses of $1 \kappa B \alpha$ degradation and STAT1 phosphorylation of BMDMs costimulated with IFN $\gamma$ and LPS for the indicated times. (C) Immunoblot analyses of STAT6 phosphorylation of BMDMs treated either with IL-4 or IL-13 for the indicated times. (D) Quantification of the immunoblot analyses of STAT6 phosphorylation in BMDMs treated with IL-13. Data are means, SEs are indicated, and $P$ values are calculated by Wilcoxon-Mann-Whitney test. $n=4$ to 6 mice per group for (A) to (D).

expression in the adipose tissue of obese mice. These results contrast with studies reporting that $\mathrm{PI} 3 \mathrm{~K} \gamma$ activity in macrophages inhibits classical macrophage activation and promotes immunosuppressive gene expression protecting tumors from $\mathrm{CD}^{+} \mathrm{T}$ cell immune response (12-15). However, mice lacking a functional PI3K $\gamma$ display a markedly impaired antiviral $\mathrm{CD}^{+} \mathrm{T}$ cell response to influenza viral infection (35), indicating that the role of $\mathrm{PI} 3 \mathrm{~K} \gamma$ in $\mathrm{CD}^{+}{ }^{+} \mathrm{T}$ cell immune response depends on the specific context. Our observation that in adipose tissue of obese mice PI3K $\gamma$ had the opposite effect on macrophage polarization than that described in tumor models indicates that PI3K $\gamma$ is not a general inhibitor of classical macrophage activation and that its role in macrophage polarization is also context-dependent. In our study, PI3K $\gamma$ activity in BMDM was required for AKT-1/2 phosphorylation in response to LPS, IFN $\gamma$, IL-4, and IL-13 but was dispensable for classical M1 activation of BMDM by LPS and IFN $\gamma$, and alternative M2 activation by IL- 4 and IL-13. This observation contrasts with studies indicating that PI3K $\gamma$ is an inhibitor of classical M1 macrophage activation (12-14). However, data from another study show a nonsignificant trend toward an increased number of M2 macrophages in the atherosclerotic lesions of $L D L R^{-1-}$ mice lacking PI3K $\gamma$ (36). Furthermore, the Zotes et al. show that PI3K $\gamma$ ablation has no effect on the expression of the M1 markers iNOS (inducible nitric oxide synthase) and $I L-12$ and of the M2 markers Arg1, $I L-10$, and YM1 in BMDMs stimulated either with LPS and IFN $\gamma$ or with IL-14 (36). These data are consistent with our results in indicating that $\mathrm{PI} 3 \mathrm{~K} \gamma$ is not a general inhibitor of classical macrophage activation and that M1- and M2-polarized gene expression can be effectively induced in macrophages lacking PI3K $\gamma$. It is remarkable that AKT-1 and AKT-2, both of which required PI3K $\gamma$ for their activation by $\mathrm{M} 1$ and $\mathrm{M} 2$ inducers, play opposite roles in $\mathrm{M} 1$ and $\mathrm{M} 2$ macrophage activation, with AKT-1 promoting M2 gene expression and AKT-2 promoting M1 gene expression (37). Therefore, the role of $\mathrm{PI} 3 \mathrm{~K} \gamma$ in macrophage activation may depend on the relative abundance of AKT-1 and AKT-2 within specific macrophage populations. In our hands, we observed several small, but significant, differences in gene expression in M1- and M2-polarized BMDMs indicating that loss of PI3K $\gamma$ causes a trend toward an M2 gene expression profile. The action of $\mathrm{PI} 3 \mathrm{~K} \gamma$ in tumor immunosuppression is proposed to depend on suppression of $\mathrm{PI} 3 \mathrm{~K} \gamma$ activity on IкB $\alpha$ degradation and nuclear factor $\kappa \mathrm{B}(\mathrm{NF}-\kappa \mathrm{B})$ activation in macrophages (14). By contrast, others propose that NF- $\mathrm{\kappa B}$ activity in macrophages promotes $\mathrm{M} 2$ macrophage polarization and maintains an immunosuppressing phenotype in tumor-associated macrophages $(38,39)$. We observed a trend for more extensive I $\mathrm{B} \mathrm{B} \alpha$ degradation in BMDMs from $\mathrm{PI} 3 \mathrm{~K}^{-/-}$mice exposed to LPS, but this difference did not achieve statistical significance, and $\mathrm{I} \kappa \mathrm{B} \alpha$ protein amounts were similar in WT and $\mathrm{PI} 3 \mathrm{~K}^{-/-}$BMDM costimulated with LPS and IFN $\gamma$. Finally, the expression of several NF- $\kappa \mathrm{B}-$ regulated genes $(T N F \alpha, I L-6, I L-1 \beta, M I P-1 \alpha, I L-1 R a$, and RANTES) was either not affected or slightly reduced by loss of PI3K $\gamma$ in activated BMDMs, indicating that PI $3 \mathrm{~K} \gamma$ is not an essential inhibitor of $\mathrm{NF}-\kappa \mathrm{B}$ in macrophages. Among the signaling pathways that we have investigated in BMDMs, the only statistically significant difference that we observed was increased STAT6 phosphorylation after 2 hours of IL-13 stimulation. A similar trend was observed for IL-4-stimulated macrophages, although it did not reach statistical significance. This prolonged STAT6 phosphorylation may explain the small trend toward M2 gene expression that we observed in $\mathrm{PI} 3 \mathrm{Kr}^{-1-}$ BMDMs exposed to M1 or M2 activation medium, which, however, is much smaller than the effect observed in vivo in adipose tissue. Overall, we conclude that $\mathrm{PI} 3 \mathrm{~K} \gamma$ controls macrophage gene expression by a mechanism that is not entirely cell-autonomous and that can lead to opposite outcomes in polarized gene expression in macrophages depending on the specific context. Several types of leukocytes are implicated in M1 polarization of adipose tissue macrophages in obesity by modulating the local abundance of IFN $\gamma$, IL-4, and IL-13 (40). In our experimental settings, macrophage polarization was not explained by local changes in these cytokines, but we observed that loss of PI3K $\gamma$ consistently reduced adipose tissue neutrophil number. Neutrophils, which are not a relevant source of IFN $\gamma$, IL-4, or IL-13, promote macrophage M1 polarization in the adipose tissue of obese mice (28). Hence, PI3K $\gamma$ may promote adipose tissue macrophage inflammatory gene expression at least in part through its action on adipose tissue neutrophil accumulation, most likely due to PI3K $\gamma$ activity in neutrophil chemotaxis (Fig. 7E). In contrast 


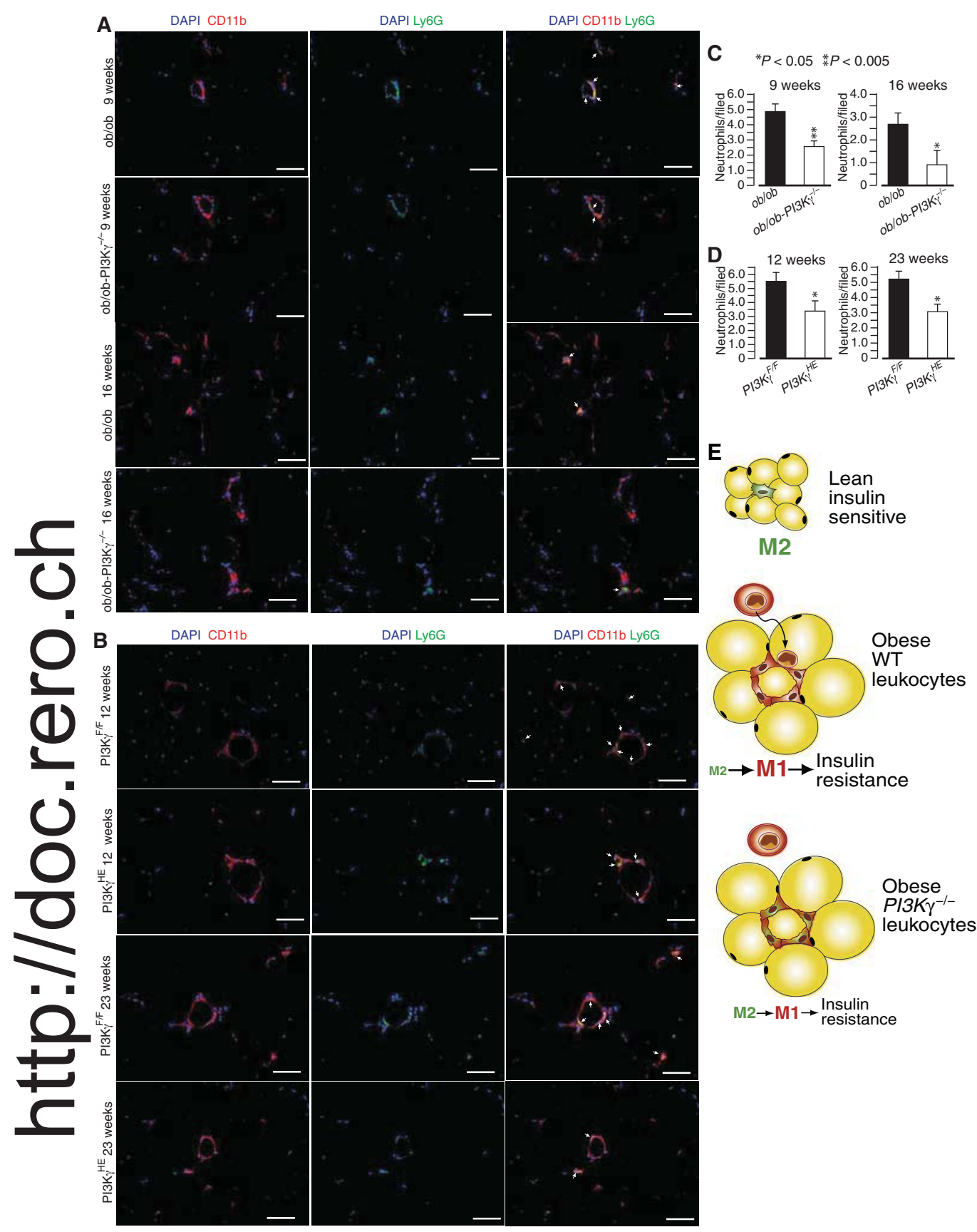

Fig. 7. PI3K $\gamma$ is required for efficient recruitment of neutrophils to adipose tissue. (A) CD11b and Ly6G immunostaining of adipose tissue sections from 8- and 16-week-old ob/ob and ob/ob-PI3K $\gamma^{-1-}$ mice. Scale bars, $100 \mu \mathrm{m}$. (B) CD11b and Ly6G immunostaining of adipose tissue sections from 12- and 23-week-old $P I 3 K_{\gamma}{ }^{H E}$ and $P I 3 K \gamma^{F / F}$ mice on a high-fat diet. Scale bars, $100 \mu \mathrm{m}$. (C) Quantification of the number of CD11 b ${ }^{+}$Ly6G ${ }^{+}$cells (neutrophils) in (A). (D) Quantification of the number of $\mathrm{CD} 11 \mathrm{~b}^{+} \mathrm{Ly}_{6 \mathrm{G}}{ }^{+}$cells (neutrophils) in (B). Data are means, SEs are indicated, and $P$ values are calculated by Student's $t$ test. $n=5$ to 13 mice per group for (A) to (D). Data are means, SEs are indicated, and $P$ values are calculated by Wilcoxon-Mann-Whitney test. (E) A model describing the effects of PI3K $\gamma$ activity in leukocytes in obesity-driven adipose tissue inflammation. In WT mice, the transition from lean to obese is characterized by leukocyte infiltration of adipose tissue and macrophage polarization toward an M1 phenotype. Mice lacking PI3K $\gamma$ in their leukocytes display reduced accumulation of adipose tissue neutrophils and reduced M1 polarization of adipose tissue gene expression, which is correlated with a delayed onset of insulin resistance.

to macrophages, neutrophils are short-lived cells with a high turnover rate that do not proliferate and that rely on PI3K $\gamma$-dependent chemotaxis to maintain their population at the site of inflammation (29). In our study, we observed a good correlation between TNF $\alpha$ mRNA abundance in adipose tissue and glucose intolerance; thus, it is possible that the transient protection observed in $o b / o b-P I 3 K^{-1-}$ and $P I 3 K \gamma^{H E}$ mice depends on reduced TNF $\alpha$ expression. TNF $\alpha$ plays a major role in the development of insulin resistance in $o b / o b$ mice and in mice on a high-fat diet (41).

Together, three major conclusions can be drawn from our study. First, the action of PI3K $\gamma$ in obesity-driven inflammation and insulin resistance depends largely on its role on adiposity, which is mediated by PI $3 \mathrm{~K} \gamma$ activity in a cell type outside the hematopoietic-endothelial compartment, and requires functional leptin signaling. Second, PI3K $\gamma$ activity in leukocytes is required for efficient polarization of inflammatory gene expression and neutrophil accumulation in adipose tissue (Fig. $7 \mathrm{E}$ ), which promotes an early onset of insulin resistance. Our third and final conclusion is that $\mathrm{PI} 3 \mathrm{~K} \gamma$ action in macrophage activation is not cell-autonomous and is context-dependent. Hence, the outcome of pharmacological strategies aiming at targeting PI $3 \mathrm{~K} \gamma$ in macrophages is not easily predictable because it may lead to opposite effects depending on the specific immune context. However, we expect that PI $3 \mathrm{~K} \gamma$ inhibition in leukocytes will delay the development of insulin resistance in obesity, providing an additional metabolic protection on top of the potent antiobesogenic effects of PI3K $\gamma$ inhibition.

\section{MATERIALS AND METHODS \\ In vivo studies}

All mice were males on $C 57 B L / 6$ genetic background and were kept at our standard facility (two to five per cage at $22^{\circ} \mathrm{C}$ under 12-hour light/12-hour dark cycles). Mice were weaned at 4 weeks of age on chow diet and, for the diet-induced obesity model, were placed on a high-fat diet, $60 \%$ of calories from fat from Bio-Serv (diet F3282), between 5 and 6 weeks of age. Littermate controls were used for mice with tissue-specific ablation of PI3K $\mathrm{r}$. Animal experiments were approved by the cantonal veterinary committee and by the Ethics Committee on Animal Care and Use in Gothenburg, Sweden. $P I 3 \mathrm{~K}^{-1-}$ mice were previously described (18), and ob/ob-PI3K $\gamma^{-1-}$ mice were obtained by crossing $P I 3 K^{-/-}$mice with $o b /+$ mice. $P I 3 K \gamma^{F / F}$ mice were obtained by crossing Pik $3 \mathrm{cg}<\mathrm{tmla}$ (EUCOMM)Wtsi $>$ /Wtsi mice [from the European Conditional Mouse Mutagenesis Program (EUCOMM)] 
with mice expressing the Flippase (FLP) recombinase under the constitutive actin promoter (fig. S4). $P I 3 K \gamma^{L y s M}$ and $P I 3 K \gamma^{H E}$ mice were generated by crossing $P I 3 K \gamma^{F / F}$ mice with transgenic mice (from the Jackson Laboratory) expressing the Cre recombinase under the control of the lysozyme-M promoter (for PI3K $\gamma^{L y s M}$ ) or the TEK (Tie2) promoter (for $P I 3 K \gamma^{H E}$ mice). Body composition was determined by soxhlet extraction, and adipocyte distribution size was performed by image analysis of tissue sections as previously described (18). For glucose tolerance and insulin tolerance, mice were fasted for 6 hours and were injected intraperitoneally with a glucose bolus of $1 \mathrm{~g} / \mathrm{kg}$ body weight (for glucose tolerance test), or with $1 \mathrm{iU}$ insulin/ $\mathrm{kg}$ (for insulin tolerance test). Tissues were collected from mice in the fed state.

\section{Cell culture studies}

BMDMs were prepared from bone marrow cells from either WT or $P I 3 \mathrm{~K}^{-1-}$ mice. Cells were differentiated in macrophages in vitro by culturing bone marrow cells in RPMI with L-glutamine supplemented with $10 \%$ fetal calf serum, $1 \%$ penicillin/streptomycin, and $1 / 10$ volume of L929 cell-conditioned medium for 6 days. For signal transduction studies, BMDMs were serum-starved for 2 hours and stimulated with LPS (100 ng), IFN $\gamma$ (150 ng), IL-13 (150 ng), or IL-4 (150 ng) for the indicated times. For in vitro differentiation into M1- or M2-activated macrophages, BMDMs were cultured for 4 or 24 hours with RPMI in the presence of either 10-ng LPS and 10-ng IFN $\gamma$ (for M1) or 10-ng IL-4 and 10-ng of IL-13 (for M2).

\section{Molecular analysis}

Total RNA was isolated from tissues by the guanidinium thiocyanate extraction method. complementary DNA was prepared using a reverse transcription kit (Promega), and qPCR was performed using a commercial SYBR green mix using specific primers (table S1). For immunoblot analysis, PI3K $\gamma$ antibodies were previously described (42); other commercial antibodies were antibodies against tubulin (Sigma), total AKT and AKT Ser ${ }^{473}$, total HSL, and phospho-specific antibodies for serines 563, 660, and 595 of HSL (Cell Signaling). Adipose tissue crown-like structure staining and quantification were performed as described (18). Adipose tissue neutrophils were quantified by immunostaining of paraffin-embedded adipose tissue sections. Antigen retrieval was performed using Dako solution (Dako). Sections were blocked with $5 \%$ bovine serum albumin in phosphatebuffered saline (PBS) 1 hour at room temperature and stained with Ly6g (1:50, 1A8, BD Bioscience) and CD11b (1:50, Abcam) overnight at $4^{\circ} \mathrm{C}$ in blocking solution. Slides were washed in PBS and incubated for 1 hour at room temperature with Alexa Fluor 488/ 594-conjugated antibody (1:200, Life Technologies). Adipose tissue neutrophils are defined as $\mathrm{CD} 11 \mathrm{~b}^{+} \mathrm{Ly}_{6 \mathrm{~g}}^{+}$cells. Cell nuclei were stained with 4',6-diamidino-2-phenylindole, images were acquired by fluorescence microscopy (Zeiss), and neutrophils were counted in five random fields per section.

\section{Statistical analysis}

Data are means, and error bars indicate SEs. $P$ values were calculated, as indicated in the figure legends, by either Wilcoxon-Mann-Whitney test or Student's $t$ test for simple comparison and by two-way ANOVA followed by Sidak when two different categorical variables are considered (such as for the glucose tolerance test and insulin tolerance test curves). Data were visually inspected by box plot before applying parametric methods. $P<0.05$ is considered statistically significant. Statistical analysis was performed with the GraphPad Prism software.

\section{SUPPLEMENTARY MATERIALS}

www.sciencesignaling.org/cgi/content/full/10/488/eaaf2969/DC1

Fig. S1. Protection from diet-induced obesity and insulin resistance, altered expression of lipidhandling genes, and increased HSL phosphorylation in $\mathrm{PISK \gamma}^{-1-}$ mice.

Fig. S2. Obesity-driven inflammation is markedly decreased in $\mathrm{PI}_{3} \mathrm{Kr}^{-1-}$ mice on a high-fat diet Fig. S3. PI3K $\gamma$ ablation in $o b / o b$ mice does not significantly affect the development of fatty liver and hepatic gene expression.

Fig. S4. Schematic representation of the targeted Pi3k allele.

Fig. S5. Deletion efficiency of PI3K $\gamma$ in $P I 3 K \gamma^{L y S M}$ mice.

Fig. S6. Lysozyme-M-CRE-mediated targeting of PI3K $\gamma$ in myeloid cells does not protect from diet-induced obesity and insulin resistance.

Fig. S7. Lysozyme-M-CRE-mediated PI3K $\gamma$ gene deletion alters the expression of markers of macrophage activation in the adipose tissue of mice with diet-induced obesity.

Fig. S8. Deletion efficiency and specificity of PI3K $\gamma$ in $P I 3 K^{H E}$ mice.

Fig. S9. PI3K $\gamma$ ablation in hematopoietic and endothelial cells does not affect hepatic inflammatory gene expression profile, steatosis, and expression of lipid metabolism genes. Fig. S10. Effects of PA on AKT phosphorylation and effects of LPS on $1 \kappa B \alpha$ degradation in WT and $P I 3 K^{-1-}$ BMDMs.

Fig. S11. Loss of PI3K $\gamma$ in leukocytes does not increase IFN $\gamma$, IL-4, or IL-13 protein abundance or endothelial cell activation in adipose tissue of obese mice.

Table S1. List of primers used for real-time qPCR.

\section{REFERENCES AND NOTES}

1. S. Virtue, A. Vidal-Puig, It's not how fat you are, it's what you do with it that counts. PLOS Biol. 6, e237 (2008).

2. R. H. Unger, G. O. Clark, P. E. Scherer, L. Orci, Lipid homeostasis, lipotoxicity and the metabolic syndrome. Biochim. Biophys. Acta 1801, 209-214 (2010).

3. G. Solinas, M. Karin, JNK1 and IKK $\beta$ : Molecular links between obesity and metabolic dysfunction. FASEB J. 24, 2596-2611 (2010).

4. G. Solinas, Molecular pathways linking metabolic inflammation and thermogenesis. Obes. Rev. 13 (Suppl. 2), 69-82 (2012).

5. P. D. Cani, Metabolism in 2013: The gut microbiota manages host metabolism.Nat. Rev. Endocrinol. 10, 74-76 (2013).

6. F. Bäckhed, H. Ding, T. Wang, L. V. Hooper, G. Y. Koh, A. Nagy, C. F. Semenkovich, J. I. Gordon, The gut microbiota as an environmental factor that regulates fat storage. Proc. Natl. Acad. Sci. U.S.A. 101, 15718-15723 (2004).

7. J. E. Burke, R. L. Williams, Synergy in activating class I PI3Ks. Trends Biochem. Sci. 40, 88-100 (2015).

8. P. T. Hawkins, L. R. Stephens, PI3K signalling in inflammation. Biochim. Biophys. Acta 1851 882-897 (2014)

9. M.P. Wymann, G. Solinas, Inhibition of phosphoinositide 3-kinase $\gamma$ attenuates inflammation, obesity, and cardiovascular risk factors. Ann. N. Y. Acad. Sci. 1280, 44-47 (2013).

10. M. P. Wymann, K. Björklöf, R. Calvez, P. Finan, M. Thomast, A. Trifilieff, M. Barbier, F. Altruda, E. Hirsch, M. Laffargue, Phosphoinositide 3-kinase $\gamma$ : A key modulator in inflammation and allergy. Biochem. Soc. Trans. 31 (Pt. 1), 275-280 (2003).

11. M. C. Schmid, C. J. Avraamides, H. C. Dippold, I. Franco, P. Foubert, L. G. Ellies, L. M. Acevedo, J. R. Manglicmot, X. Song, W. Wrasidlo, S. L. Blair, M. H. Ginsberg, D. A. Cheresh, E. Hirsch, S. J. Field, J. A. Varner, Receptor tyrosine kinases and TLR/LL1Rs unexpectedly activate myeloid cell PI3k $\gamma$, a single convergent point promoting tumor inflammation and progression. Cancer Cell 19, 715-727 (2011).

12. L. Luo, A. A. Wall, J. C. Yeo, N. D. Condon, S. J. Norwood, S. Schoenwaelder, K. W. Chen, S. Jackson, B. J. Jenkins, E. L. Hartland, K. Schroder, B. M. Collins, M. J. Sweet, J. L. Stow, Rab8a Interacts directly with PI3K $\gamma$ to modulate TLR4-driven PI3K and mTOR signalling. Nat. Commun. 5, 4407 (2014)

13. M. M. Kaneda, P. Cappello, A. V. Nguyen, N. Ralainirina, C. R. Hardamon, P. Foubert, M. C. Schmid, P. Sun, E. Mose, M. Bouvet, A. M. Lowy, M. A. Valasek, R. Sasik, F. Novelli, E. Hirsch, J. A. Varner, Macrophage PI3K $\gamma$ drives pancreatic ductal adenocarcinoma progression. Cancer Discov. 6, 870-885 (2016).

14. M. M. Kaneda, K. S. Messer, N. Ralainirina, H. Li, C. J. Leem, S. Gorjestani, G. Woo, A. V. Nguyen, C. C. Figueiredo, P. Foubert, M. C. Schmid, M. Pink, D. G. Winkler, M. Rausch, V. J. Palombella, J. Kutok, K. McGovern, K. A. Frazer, X. Wu, M. Karin, R. Sasik, E. E. W. Cohen, J. A. Varner, PI3K $\gamma$ is a molecular switch that controls immune suppression. Nature 539, 437-442 (2016).

15. O. De Henau, M. Rausch, D. Winkler, L. Felipe Campesato, C. Liu, D. Hirschhorn Cymerman, S. Budhu, A. Ghosh, M. Pink, J. Tchaicha, M. Douglas, T. Tibbitts, S. Sharma, J. Proctor, N. Kosmider, K. White, H. Stern, J. Soglia, J. Adams, V. J. Palombella, K. McGovern, J. L. Kutok, J. D. Wolchok, T. Merghoub, Overcoming resistance to checkpoint blockade therapy by targeting PI3K $\gamma$ in myeloid cells. Nature 539, 443-447 (2016).

16. A. Perino, A. Ghigo, E. Ferrero, F. Morello, G. Santulli, G. S. Baillie, F. Damilano, A. J. Dunlop, C. Pawson, R. Walser, R. Levi, F. Altruda, L. Silengo, L. K. Langeberg, G. Neubauer, 
S. Heymans, G. Lembo, M. P. Wymann, R. Wetzker, M. D. Houslay, G. laccarino, J. D. Scott, E. Hirsch, Integrating cardiac $\mathrm{PIP}_{3}$ and $C A M P$ signaling through a PKA anchoring function of p110\%. Mol. Cell 42, 84-95 (2011).

17. E. Patrucco, A. Notte, L. Barberis, G. Selvetella, A. Maffei, M. Brancaccio, S. Marengo, G. Russo, O. Azzolino, S. D. Rybalkin, L. Silengo, F. Altruda, R. Wetzker, M. P. Wymann, G. Lembo, E. Hirsch, PI3K $\gamma$ modulates the cardiac response to chronic pressure overload by distinct kinase-dependent and -independent effects. Cell 118, 375-387 (2004).

18. B. Becattini, R. Marone, F. Zani, D. Arsenijevic, J. Seydoux, J.-P. Montani, A. G. Dulloo, B. Thorens, F. Preitner, M. P. Wymann, G. Solinas, PI3K $\gamma$ within a nonhematopoietic cell type negatively regulates diet-induced thermogenesis and promotes obesity and insulin resistance. Proc. Natl. Acad. Sci. U.S.A. 108, E854-E863 (2011).

19. N. Kobayashi, K. Ueki, Y. Okazaki, A. Iwane, N. Kubota, M. Ohsugi, M. Awazawa, M. Kobayashi, T. Sasako, K. Kaneko, M. Suzuki, Y. Nishikawa, K. Hara, K. Yoshimura, I. Koshima, S. Goyama, K. Murakami, J. Sasaki, R. Nagai, M. Kurokawa, T. Sasaki, T. Kadowaki, Blockade of class IB phosphoinositide-3 kinase ameliorates obesity-induced inflammation and insulin resistance. 108, 5753-5758 Proc. Natl. Acad. Sci. U.S.A. (2011).

20. A. Ortega-Molina, E. Lopez-Guadamillas, J. A. Mattison, S. J. Mitchell, M. Muñoz-Martin, G. Iglesias, V. M. Gutierrez, K. L. Vaughan, M. D. Szarowicz, I. González-García, M. López, D. Cebrián, S. Martinez, J. Pastor, R. de Cabo, M. Serrano, Pharmacological inhibition of PI3K reduces adiposity and metabolic syndrome in obese mice and rhesus monkeys. Cell Metab. 21, 558-570 (2015).

21. A. Perino, M. Beretta, A. Kilić, A. Ghigo, D. Carnevale, I. Enrico Repetto, L. Braccini, D. Longo, M. Liebig-Gonglach, T. Zaglia, R. lacobucci, M. Mongillo, R. Wetzker, M. Bauer, S. Aime, A. Vercelli, G. Lembo, A. Pfeifer, E. Hirsch, Combined inhibition of PI3K $\beta$ and PI3K $\gamma$ reduces fat

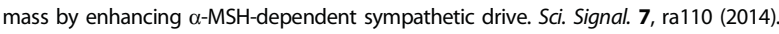

22. K. Lolmede, L. Campana, M. Vezzoli, L. Bosurgi, R. Tonlorenzi, E. Clementi, M. E. Bianchi, G. Cossu, A. A. Manfredi, S. Brunelli, P. Rovere-Querini, Inflammatory and alternatively activated human macrophages attract vessel-associated stem cells, relying on separate HMGB1- and MMP-9-dependent pathways. J. Leukoc. Biol. 85, 779-787 (2009).

23. V. Bourlier, A. Zakaroff-Girard, A. Miranville, S. De Barros, M. Maumus, C. Sengenes, J. Galitzky, M. Lafontan, F. Karpe, K. N. Frayn, A. Bouloumié, Remodeling phenotype of human subcutaneous adipose tissue macrophages. Circulation 117, 806-815 (2008).

24. V. Apostolopoulos, M. P. J. de Courten, L. Stojanovska, G. L. Blatch, K. Tangalakis, B. de Courten, The complex immunological and inflammatory network of adipose tissue in obesity. Mol. Nutr. Food Res. 60, 43-57 (2015).

25. C. N. Lumeng, I. Maillard, A. R. Saltiel, T-ing up inflammation in fat. Nat. Med. 15, 846-847 (2009).

26. D. A. Winer, S. Winer, M. H. Chng, L. Shen, E. G. Engleman, B Lymphocytes in obesityrelated adipose tissue inflammation and insulin resistance. Cell. Mol. Life Sci. $\mathbf{7 1}$ 1033-1043 (2014)

27. Y. Tang, A. Harrington, X. Yang, R. E. Friesel, L. Liaw, The contribution of the Tie $2^{+}$lineage to primitive and definitive hematopoietic cells. Genesis 48, 563-567 (2010).

28. S. Talukdar, D. Y. Oh, G. Bandyopadhyay, D. Li, J. Xu, J. McNelis, M. Lu, P. Li, Q. Yan, Y. Zhu J. Ofrecio, M. Lin, M. B. Brenner, J. M. Olefsky, Neutrophils mediate insulin resistance in mice fed a high-fat diet through secreted elastase. Nat. Med. 18, 1407-1412 (2012).

29. E. Hirsch, V. L. Katanaev, C. Garlanda, O. Azzolino, L. Pirola, L. Silengo, S. Sozzani, A. Mantovani, F. Altruda, M. P. Wymann, Central role for G protein-coupled phosphoinositide 3-kinase gamma in inflammation. Science 287, 1049-1053 (2000).

30. F. J. Cubero, M. E. Zoubek, W. Hu, J. Peng, G. Zhao, Y. A. Nevzorova, M. Al Masaoudi, L. P. Bechmann, M. V. Boekschoten, M. Muller, C. Preisinger, N. Gassler, A. E. Canbay, T. Luedde, R. J. Davis, C. Liedtke, C. Trautwein, Combined activities of JNK1 and JNK2 in hepatocytes protect against toxic liver injury. Gastroenterology 150, 968-981 (2016).

31. C. N. Lumeng, J. L. Bodzin, A. R. Saltiel, Obesity induces a phenotypic switch in adipose tissue macrophage polarization. J. Clin. Invest. 117, 175-184 (2007).

32. C. N. Lumeng, S. M. Deyoung, J. L. Bodzin, A. R. Saltiel, Increased inflammatory properties of adipose tissue macrophages recruited during diet-induced obesity. Diabetes 56, 16-23 (2007).
33. M. E. Shaul, G. Bennett, K. J. Strissel, A. S. Greenberg, M. S. Obin, Dynamic, M2-like remodeling phenotypes of $\mathrm{CD} 11 \mathrm{c}+$ adipose tissue macrophages during high-fat dietInduced obesity in mice. Diabetes 59, 1171-1181 (2010).

34. M. Zeyda, D. Farmer, J. Todoric, O. Aszmann, M. Speiser, G. Györi, G. J. Zlabinger, T. M. Stulnig, Human adipose tissue macrophages are of an anti-inflammatory phenotype but capable of excessive pro-inflammatory mediator production. Int. J. Obes. 31, 1420-1428 (2007).

35. S. P. Nobs, C. Schneider, A. K. Heer, J. Huotari, A. Helenius, M. Kopf, PI3K $\gamma$ is critical for dendritic cell-mediated CD8 $+\mathrm{T}$ cell priming and viral clearance during influenza virus infection. PLOS Pathog. 12, e1005508 (2016).

36. T. M. Zotes, C. F. Arias, J. J. Fuster, R. Spada, S. Pérez-Yagüe, E. Hirsch, M. Wymann A. C. Carrera, V. Andrés, D. F. Barber, PI3K p110 $\gamma$ deletion attenuates murine atherosclerosis by reducing macrophage proliferation but not polarization or apoptosis in lesions. PLOS ONE 8, e72674 (2013).

37. A. Arranz, C. Doxaki, E. Vergadi, Y. Martinez de la Torre, K. Vaporidi, E. D. Lagoudaki, E. leronymaki, A. Androulidaki, M. Venihaki, A. N. Margioris, E. N. Stathopoulos, P. N. Tsichlis, C. Tsatsanis, Akt1 and Akt2 protein kinases differentially contribute to macrophage polarization. Proc. Natl. Acad. Sci. U.S.A. 109, 9517-9522 (2012).

38. C. H. Fong, M. Bebien, A. Didierlaurent, R. Nebauer, T. Hussell, D. Broide, M. Karin, T. Lawrence, An antiinflammatory role for IKK $\beta$ through the inhibition of "classical" macrophage activation. J. Exp. Med. 205, 1269-1276 (2008).

39. T. Hagemann, T. Lawrence, I. McNeish, K. A. Charles, H. Kulbe, R. G. Thompson, S. C. Robinson, F. R. Balkwill, "Re-educating" tumor-associated macrophages by targeting NF-kB. J. Exp. Med. 205, 1261-1268 (2008).

40. A. Castoldi, C. Naffah de Souza, N. O. S. Câmara, P. M. Moraes-Vieira, The macrophage switch in obesity development. Front. Immunol. 6, 637 (2016).

41. K. T. Uysal, S. M. Wiesbrock, M. W. Marino, G. S. Hotamisligil, Protection from obesity-induced insulin resistance in mice lacking TNF- $\alpha$ function. Nature 389, 610-614 (1997).

42. T. Bondeva, L. Pirola, G. Bulgarelli-Leva, I. Rubio, R. Wezker, M. P. Wymann, Bifurcation of lipid and protein kinase signals of PI3K $\gamma$ to the protein kinases PKB and MAPK. Science 282, 293-296 (1998).

Funding: This work is supported by a grant from the Swedish Research Council (grant 2014-3019), the Swedish Diabetes Foundation (DIA2014-069), the Novo Nordisk Foundation (NNF140C0010919, a startup fund from the University of Gothenburg), the Diabetes and Cancer Research Programme of the European Foundation for the Study of Diabetes, and the Swiss National Science Foundation (SNSF) (Sinergia grant 154499 to G.S. and C.R., SNSF project grant 152998 to G.S. and M.P.W., and the SNSF project grants 153211/1 and 164085 to M.P.W.). Author contributions: G.S. and M.P.W. conceived and designed the experiments. L.B. and B.B. performed most experiments. L.B., B.B., C.S., M.P.W., and G.S. analyzed data and interpreted the results. C.S., A.M., and F.Z. performed experiments. R.M., F.B., M.B., C.R., and M.P.W. provided the conditional KO mice. G.S. wrote the manuscript, and all the authors reviewed and approved the manuscript. Competing interests: The authors declare that they have no competing interests.

Submitted 21 January 2016

Resubmitted 9 February 2017

Accepted 28 June 2017

Published 18 July 2017

10.1126/scisignal.aaf2969

Citation: L. Breasson, B. Becattini, C. Sardi, A. Molinaro, F. Zani, R. Marone, F. Botindari, M. Bousquenaud, C. Ruegg, M. P. Wymann, G. Solinas, PI3K $\gamma$ activity in leukocytes promotes adipose tissue inflammation and early-onset insulin resistance during obesity. Sci. Signal. 10, eaaf2969 (2017). 